\title{
Projeto de Extensão em Sexualidade Humana na Educação
}

\section{Extension Project on Human Sexuality in Education}

\author{
Walfrido Menezes \\ Faculdade Estácio do Recife \\ walfridomenezes@uol.com.br \\ Marília Araújo \\ Faculdade Estácio do Recife \\ Maíra Souza \\ Faculdade Estácio do Recife \\ Rafaela Ingrid Melo \\ Faculdade Estácio do Recife
}

\section{Resumo}

O presente trabalho - um relato de experiência -, sobre a sexualidade e a questão da gravidez adolescente, tem como objetivo resgatar e favorecer o processo de crescimento do sujeito adolescente, em seu contexto sociocultural, possibilitando uma nova leitura e re-leitura dos preconceitos, tabus e dogmas etc. A partir de uma ótica biopsicossocial, política, afetiva, ideológica, cultural e educacional, contemplada pela tríade autonomia, autoestima e afetividade $\mathrm{O}$ pressente trabalho, teve e tem como metodologia a dinâmica de grupo, a observação, o grupo focal e o sociodrama. O projeto de extensão envolve um grupo de jovens moradores da comunidade do Prado e adjacências; mães da comunidade e os participantes do Projeto Cidadania e o Recriar, que funcionam desde 2005.

Palavras-chave: Extensão Sexualidade; Educação Sexual; Gravidez na Adolescência

\begin{abstract}
This paper - an experience report -, on sexuality and the issue of teenage pregnancy, aims to restore and favor the growing-up process of the adolescent person, in his sociocultural context, allowing for a new interpretation and reinterpretation of prejudices, taboos, and dogmas, etc., from a biopsychological, political, affective, ideological, cultural and educational perspective, contemplated by the triad autonomy, self-esteem and affection. The study presented here used and uses a methodology of group dynamics, observation, focus group and sociodrama. The extension project involves a group of young residents of the Prado community and vicinity, mothers from the community and the participants of the Projeto Cidadania e o Recriar (Citizenship and Rebuilding Project), that has been in place since 2005.
\end{abstract}

Keywords: Sexuality Extension; Sex Education; Teenage Pregnancy 


\section{Introdução}

O Projeto de Extensão em Sexualidade Humana, realizado na Faculdade Estácio do Recife é o resultado do trabalho e compromisso social da psicologia, em atuação junto às classes populares, que buscam informações sobre educação sexual, sendo desenvolvido desde 2005. Contempla tanto os participantes do Recriar, que são crianças com idade igual ou superior a 11 anos. Quanto os participantes do Agente de Cidadania, que são os adolescentes e adultos. Tanto o Recriar como o Agente de Cidadania são projetos sociais coordenados por docentes da Faculdade Estácio do Recife.

A partir dos grupos citados anteriormente, surge o trabalho do Projeto de Extensão em Sexualidade Humana, que tem como objetivo viabilizar uma ação em torno da educação sexual, de forma dinâmica e participativa, possibilitando os participantes serem protagonistas de suas questões. Desta maneira, os mesmos passaram a interagir nas atividades falando sobre o cotidiano que envolve a questão da sexualidade.

A tentativa do projeto é a de ampliar a visão da função da educação sexual, mostrando que esta é capaz de promover uma reflexão sobre o amor, relacionamentos afetivos, condutas diante das diversidades sexuais, aborto, violência sexual, papéis de gênero e a gravidez na adolescência não planejada e não desejada, entre outros; desmistificando a crença de que a educação sexual tem como papel exclusivo a prevenção de doenças sexualmente transmissíveis e gravidez não planejada, procurando promover debates sobre temas da sexualidade humana.

Os instrumentos utilizados, como via de discussão, são os vídeos didáticos, slides, dinâmicas de grupo, sociodrama e simples esclarecimentos de dúvidas no campo da sexualidade. Importante ressaltar que todos os debates e esclarecimentos de dúvidas têm embasamento teórico, adquirido através das capacitações contínuas que os monitores recebem do seu orientador.

Portanto, o presente trabalho voltou-se para a juventude. Visto que na atual contemporaneidade o jovem encontra-se em um ambiente impregnado de mudanças, consumo, mídias e faltas de valorização ética frente à vida.

\section{Juventude: 0 ser adolescente}

A juventude hoje, independente de classe social, tem acesso a maiores informações e conhecimentos, estando mais exposta às contradições sociais. Falta, portanto, uma construção crítica e criativa pelos adolescentes para que possam integrar as suas perspectivas de vida.

O mundo evoluiu, as posições mais tradicionais e repressoras perderam grande parte do sentido para os jovens de hoje, inseridos numa visão pseudo-erótica, na qual o sexo vira mercadoria de consumo especialmente na tevê. Os jovens de hoje se encontram à mercê dessa contradição.

O sexo, na opinião das adolescentes que participaram da pesquisa em Caruaru (MENEZES, 2002), para nove delas veio através da televisão, novelas, debates, filmes, etc. Uma chegou a afirmar que aprendeu na tevê, que é no sexo que mais se fala. "Através de histórias de prostitutas e através das novelas" (Carolina, 15 anos). Somando tevê e revistas, aprendemos que na opinião das adolescentes, a descoberta do sexo deu-se através destes dois meios em $60 \%$ dos casos.

Com efeito, a imagem transmitida pelos multimeios - em especial a televisão - exerce no sujeito uma forte pressão, estimulando as áreas sensoriais, cognitivas, sensitivas e perceptivas, visto que tornam presentes os acontecimentos. Desta maneira, ela mexe com os conteúdos sociais e afetivos que são à base de nossa organização, enquanto indivíduos e quando distorcidos fragmentam as relações sociais e humanas.

Os meios de comunicação não oferecem uma compreensão educativa, utilizam-se de um processo em que o corpo torna-se o centro das questões - de maneira pseudo-erótica, para a venda do produto, principalmente com a figura feminina.

Para a sobrevivência do mercado:

a cultura do consumo recebe melhor apoio de mercados compostos de clones sexuais, homens que desejam objetos e mulheres que desejam ser objetos, enquanto o objeto desejado é sempre mutante, descartável e determinado pelo mercado (WOOLF, 1992, p.190, apud MENEZES, 2002).

E como observou Baudrillard (1995, p. 143):

a homologia do corpo e dos objetos introduz mecanismos profundos do consumo dirigido. Se a 'redescoberta do corpo' é sempre a do corpo / objeto no contexto generalizado dos outros objetos, percebe-se como é fácil, lógica e necessária a transição de bens e de objetos na compra.

Na sociedade, baseada no capitalismo, inviabilizase de certa maneira a importância amorosa, pois para o

Walfrido Nunes Menezes, Marília Araújo, Maíra Souza e Rafaela Ingrid Melo 
capital:

o surgimento de contingentes de homens que passassem a ter um amor verdadeiro e apaixonado pelas mulheres, sua substancial autoridade e dinheiro poderiam desertar para unir suas forças às de oposição (WOOLF, 1992, p. 189, apud MENEZES, 2002).

E, completa Bourdieu (1997, p.78):

Os homens ou as mulheres têm sua responsabilidade, mas que eles ou elas são em grande parte definidos em suas possibilidades e suas impossibilidades pela estrutura na qual estão situados e pela posição que ocupam nessa estrutura (...) o Público não é esclarecido e consciente das manipulações que sofre.

Na opinião de Remédios (1997, p. 01), a televisão "vem completar algo que, por ventura, possa lhe faltar, dando a sensação de gratificação, que nada lhe falta, podendo, com sua onipotência, manipular o mundo e negar a condição real de frustração". Projetam-se na tela os desejos inalcançáveis ou substitutos do vazio provocado pela ausência de referências diante do cotidiano como falta de trabalho, lazer, segurança, escola, saúde, laços familiares amorosos etc. No Brasil, "sua força reside no fato de que ela fomenta a crença de que não existem fronteiras entre ficção e realidade" (NOLASCO, 1998, p. 147).

Por exemplo, as novelas:

tentam imitar a vida e, ao fazê-lo, criam padrões de comportamentos virtuais, fundados por uma moral que valoriza a aquisição de bens materiais, é permissiva e orientada para o consumo. Ela representa um mundo onde o pensamento é débil, as convicções não têm firmeza, e as atitudes individuais são de indiferença (...) mas sem o menor respaldo de conteúdos ou consistência (id., 1998, p. 148 - 150).

Assim, no exemplo da gravidez na adolescência, encontramos em Corder-Bolz (1981, apud MENEZES, 2002, p. 41), um esclarecimento importante, ao apontar em depoimento sobre a temática, que as adolescentes grávidas:

estavam duas vezes mais propensas a pensar que os relacionamentos da tevê são como relacionamentos na vida real, do que adolescentes não-grávidas, e que as personagens da tevê não usariam contraceptivos, quando envolvidas em um relacionamento sexual.

Diante de exposto, percebemos que a adolescência é uma fase da vida que implica profundas transformações que vão do físico, de ordem biológica na puberdade, com o aumento na produção dos hormônios sexuais, ao psicológico, estruturando-se e recebendo influência do e no social. Ela resulta em conflitos, diante da busca de identidade pessoal, social, sexual e de gênero. Do ponto de vista psicossocial, ampliam-se os sentimentos e as emoções. O flerte, o desejo, o namoro aumenta, saindo do autoerotismo para o heteroerotismo como reflexo da pulsão sexual; as e os adolescentes fogem das relações parentais e egocêntricas, procurando uma abertura maior em relação ao grupo, pela busca de sua identidade.

Nessa fase, tudo muda não se é mais como se era na infância. Aparecem muitas dúvidas na adolescência. $\mathrm{O}$ indivíduo torna-se adulto, embora o grupo ache 'que ainda é criança'. Surge, assim, uma ambivalência entre o ser criança, se divertir e o ser adulto, assumir compromissos. A adolescência caracteriza-se por apresentar comportamentos diferenciados tais como: atitudes de inquietação, impulsividade, submissão, insegurança, introversão e/ou extroversão, porém frutos das transformações biopsicossociais, pelos quais se passa.

Assim, não se pode mais pensar na adolescência como uma fase de irresponsabilidade e imaturidade, de condutas turbulentas e dispersivas, pois a "adolescência é mais do que uma etapa estabilizadora. É um caminho no contexto da realidade humana" (KNOBEL, 1988, apud MENEZES, 2002, p. 29). Tal processo é caracterizado por etapas chamadas pelo autor de Síndrome da Adolescência Normal, constituída por três aspectos:

A mudança do corpo infantil está ligada às transformações biológicas na puberdade; ela se desenvolve de maneira incontrolável e provoca uma ansiedade até a reformulação da imagem corporal - mental - e do não ser mais criança, o que é estabelecido pela aceitação do novo corpo. (...) Outro ponto que caracteriza os/as adolescentes é a sua relação com os pais, a perda da identidade infantil. Enquanto na infância esses são idealizados como super-

Walfrido Nunes Menezes, Marília Araújo, Maíra Souza e Rafaela Ingrid Melo 
heróis, na adolescência são alvos de críticas. Essa nova visão provoca nos/nas adolescentes estados que misturam agressividade, culpa, avanços e regressões, liberdade e submissão, segurança e insegurança. (...) A perda da identidade e o enfraquecimento do papel sócio familiar geram no grupo de pares a busca de novas perspectivas de formar uma identidade própria, a partir da identidade familiar e da identificação com o grupo - identidade coletiva. (MENEZES, 2002, p. 29).

De acordo com a posição de Tap (apud SANTOS, 1998, p. 152 - 153):

o sujeito constrói seu lugar e assume suas posições na sociedade através da apropriação da cultura e das instituições sociais mediadas pelo outro. A identidade, portanto, forma-se no jogo das relações sociais na medida em que o sujeito se apropria das regras, valores, normas e formas de pensar de sua cultura. (...) Portanto, articula a noção de identidade social e pessoal, considerando que elas se justapõem.

Nesse sentido, a participação da família em seus diversos arranjos, é fundamental para a organização do indivíduo, em termos de construção do processo de estruturação da identidade, através da tríade: autonomia, autoestima e afetividade. A autonomia é entendida aqui como o processo em que os pais possibilitam aos filhos a busca de caminhos próprios com a maior independência possível.

A autoestima é o resultado das referências, experiências, ideias e sensações que adquirimos desde a gravidez até a idade adulta. Cada sujeito vai elaborar uma ideia valorativa de sua pessoa, em relação a si e aos outros. Esse processo é organizado desde o eu corporal (como me vejo) até as atitudes positivas desenvolvidas pela família e sociedade para com o indivíduo.

Enfim, aparece a afetividade, que seria o processo em que as relações familiares se estabelecem a partir de relações amorosas e carinhosas dos pais entre si, com os filhos e entre irmãos. Relações estabelecidas no amor desenvolvem potenciais humanos $\mathrm{e}$ construidores do equilíbrio e bem-estar humano e social.

Assim, diante de tais mudanças, embora essenciais ao desenvolvimento humano, aparecem variações significativas na vida dos/das jovens, tais como: maior maturidade, passagem para o mundo adulto, maior socialização, bem como, o flerte, o ficar, o namoro, etc. Todas essas mudanças implicam, agora também, em uma sexualidade mais voltada para o/a outro (a), o que promove uma ampliação do processo de socialização, como também conflitos nas escolhas e direção a serem seguidas na vida.

Por entender que a juventude é uma fase que implica profundas transformações que vão do físico ao psicológico, estruturando-se e recebendo influência do/no social; é que se percebe a importância de trabalhar a sexualidade de maneira dinâmica, criativa e reflexiva. Embora, torna-se importante, discutir a sexualidade na educação não estamos excluindo o papel da família, uma vez que, são as mesmas que se encontram mais próximas dos filhos; e sendo os jovens seus filhos e filhas que convivem no cotidiano, envolvem o campo emocional, além do racional, visto que a mesma resulta em conflitos, diante da busca e identidade pessoal, social, sexual e de gênero.

Não podemos esquecer que o adolescente deve ser visto em um contexto familiar. No final do século XVI e início do XVII, foi consolidado social e politicamente um sentimento de família que estimula o privado e a intimidade, embora na estrutura social dos privilegiados.

Ariés (apud CHAVES, 1997, p.17), portanto, observa que "a estrutura de família até o século XVII era vivida em 'público' (...) a família não existia como sentimento ou como amor, mas sim como realidade vivida, uma realidade moral e social mais do que sentimental. Seu papel era assegurar a transmissão da vida, dos bens e do nome".

Durand (1999, p.6) aponta que no Brasil:

essa definição de família tida como ideal foi importada da Europa, enquanto a sua história também só tem a ver com a historia das sociedades europeias, a revolução industrial, o abandono do campo, a instalação da família então 'reduzida' aos elementos que são o pai, a mãe e os filhos.

Por outro lado, os demais grupos sociais, só no século XVIII, "se encaixam neste novo conceito de família" (CHAVES, 1997, p.18). A partir do século XVIII ocorreu a "privatização da família, acompanhada da privatização da propriedade e da apropriação do produto do trabalho" (CHAUÍ, 1984, p.130):

A família tradicional, seja ela burguesa ou trabalhadora, realiza a socialização de seus membros através da figura paterna que se

Walfrido Nunes Menezes, Marília Araújo, Maíra Souza e Rafaela Ingrid Melo 
situa como mediadora entre família e sociedade - através do trabalho - e entre ela e o Estado - através do casamento civil (CHAUÍ, 1984, p. 135).

Do ponto de vista religioso, no Brasil, a estrutura da família:

tem recebido um tratamento religioso católico, com fortes conotações europeizadas, calcadas na ideia de famíliapadrão, higienizada e patriarcal, com presença marcante do moralismo e do controle sexual, típico desta matriz ideológica (NEDER, 1998, p. 34).

Por outro lado, segundo Chauí (1984, p. 140):

a família se organiza mediante o sacramento, tendo na versão religiosa, a cerimônia do casamento uma "dupla finalidade de garantir, por um lado, a circunscrição da sexualidade feminina e, por outro lado, a subordinação da esposa ao marido, na versão civil (contrato) (...) o que estabelece a desigualdade (...) sem igualdade e sem a liberdade não há contrato, mas hierarquia, subordinação, mando, desigualdade e domínio.

Nos últimos 30 anos, a sociedade e a família passaram por grandes transformações. Enquanto na década de 50 e 60 , o casamento era o ponto central para justificar o relacionamento sexual e o nascimento dos filhos, a partir do fim da década de 60 e início de 70, com os movimentos hippies, a pílula, a música, etc., ocorre uma revolução na família, com o movimento feminista, a saída da mulher para a universidade e o trabalho, passando ela a ter controle sobre o corpo.

Nesse contexto, as bases familiares começaram a ser questionadas, principalmente em termos de espaço privado para as mulheres e de público só para os homens. No espaço público a mulher começou a promover várias mudanças sociais, entre elas: a da submissão, da dependência, do machismo, do casamento tradicional etc. $\mathrm{O}$ seguinte passo foi desvincular o sexo do casamento, o que possibilitou uma maior liberdade da mulher.

Observamos hoje, entre os jovens, uma

inversão ou negação da moral sexual tradicional e ainda do casamento religioso e civil como modelo de família, negação da procriação como proposta de vida a dois e sim por escolha, questionar a estrutura segmentada dos papéis masculinos e femininos, desejando atração, ternura e amor nas relações ...(CHAUÍ, 1984, p. 139).

\section{Sexualidade e educação sexual}

Partindo do pressuposto que esta fase vem impregnada de dúvidas e ideias preconcebidas, elaboramos um projeto formativo e informativo em uma ótica educacional, que visa o esclarecimento das questões concernentes à sexualidade humana e saúde sexual e reprodutiva. Sexualidade é a essência da vida humana, envolvendo o conjunto de características biológicas, psicológicas e socioculturais que nos permitem compreender o mundo e vivê-lo através do nosso corpo e em torno do prazer saudável e harmonioso com a vida, enquanto mulher e homem.

Já o sexo seria a base biológica, propriamente dita, isto é, o corpo como características anatômicas e fisiológicas que nos diferenciam enquanto feminino vulva e aparelho reprodutor - e o masculino - pênis e aparelho reprodutor.

Portanto, entendemos a leitura da sexualidade numa visão bio-psicossociocultural em um contexto político, ideológica e educacional contemplada pela tríade: autonomia, autoestima e afetividade para a formação da identidade pessoal e de gênero que possibilita ao indivíduo equilíbrio, conhecimento e consciência de si para saber lidar com seus desejos e chegar ao passo fundamental para o encontro e conhecimento do outro.

Assim, o trabalho em sexualidade humana, numa ótica educacional, passa por uma fusão com o todo e precisa da reflexão do 'eu' indivíduo para se chegar à relação 'eu-tu', ou seja, o estabelecimento das relações humanas.

\section{Saúde sexual, saúde reprodutiva}

O programa proposto para o projeto de extensão, dentre outros, compreende as seguintes etapas: a História da Sexualidade Através dos Tempos; Corpo Reprodutivo; Amar, Namorar e Ficar; Ser Homem e Ser Mulher; Gravidez na Adolescência: Estudo de Caso, etc.

As atividades desenvolvidas buscavam e busca viabilizar uma ação em torno da educação sexual, através das políticas públicas sociais, junto ao público jovem e seguindo os princípios dos Direitos Humanos. $\mathrm{O}$ trabalho é realizado de forma dinâmica e participativa; promovendo uma ação por parte dos participantes como protagonistas se suas questões,

Walfrido Nunes Menezes, Marília Araújo, Maíra Souza e Rafaela Ingrid Melo 
fazendo com que eles interagissem uns com os outros, falando sobre o cotidiano que envolve a questão da sexualidade.

A partir de uma abordagem sistematizada, aliada a troca de informações que facilitem aos educando vivenciarem com mais consciência e autonomia a sua própria sexualidade (formação), o trabalho de Educação Sexual deve apontar para que a escola assuma sua função educadora, suplantando os falsos conceitos e a falsa moral, com ações simples, honestas e coerentes com a vida social, afetiva, cultural, política e educacional.

Para tanto, faz-se necessário o enfoque tanto biológico, quanto psicológico, social, cultural, político, ideológico e educacional, viabilizando no ser humano a paixão, o afeto, o desejo, a vontade, o amor e o prazer, para que a mulher e o homem sejam sujeitos construtores dos seus valores, ideias, ternura e afeto.

Assim, surge dentre outros aspectos da sexualidade humana, a gravidez na adolescência e os preconceitos e exclusões - foco do trabalho - que, no Brasil, é uma questão bastante ampla e de pouco estudo, tanto na teoria como na prática.

Aqui destacamos a questão da gravidez adolescente e dos preconceitos, por terem sido inclusive a preocupação inicial que teve o grupo do Projeto Recriar, do curso de Psicologia e o de Agentes de Cidadania do curso de Direito da Faculdade Estácio do Recife, para a vivência do referido projeto junto a préadolescentes, jovens e adultos - a juventude - da comunidade do Prado e adjacências.

Em relação à gravidez se encontram poucas publicações (livros) e alguns textos em revistas, temas para seminários e via Internet, mas sempre com o olhar do adulto ou do médico científico e sem focalizar a questão da exclusão e o olhar da juventude.

A área médica que lida diretamente com esse setor - a ginecologia - apresentam mais estudos sobre a gravidez da mulher adulta do que sobre a gravidez das jovens, embora existam hoje algumas instituições hospitalares em Recife/Pernambuco, como o Instituto Materno Infantil - IMIP, o Hospital Agamenon Magalhães, o Otávio de Freitas e a Maternidade da Encruzilhada, além de algumas Organizações não governamentais e os Programas de Saúde da Família, que através de uma equipe multidisciplinar, vêm desenvolvendo um trabalho com adolescentes no acompanhamento à gravidez. $\mathrm{Na}$ maioria dos casos são ações desenvolvidas com as adolescentes já grávidas.

A gravidez na adolescência tem preocupado vários países do mundo, incluindo o Brasil, face ao crescimento no processo de fecundidade junto a este público, que a cada ano que se passa ainda tende a piorar com a diminuição da idade - atualmente entre
10 e 14 anos, da primeira gestação.

Porém, o foco de atenção deste grupo de extensão não é o número de adolescentes grávidas, mas sim a preocupação com uma situação que as afasta as mesmas da escola, de um trabalho melhor, etc., ampliando assim o processo de exclusão social.

Assim, a gravidez na adolescência termina promovendo uma maior exclusão, visto que as jovens, na maioria das vezes, das classes populares, já se encontram desprovidas de condições básicas de vida e fora da escola; ou, em outros casos, promove o afastamento das mesmas, o que termina por implicar uma baixa escolarização, resultando na desqualificação e na exclusão do processo de trabalho; restam, assim, poucas opções e, em geral, na área informal de trabalho.

Por outro lado, paralela a essa questão, ainda existe o caso do aborto, que temos que focalizar frente ao índice elevado no país. No que se referem ao Brasil, os dados são conflitantes e opostos, se analisarem as condições de vida da mãe e do pai e a classe social da qual fazem parte.

Já a mortalidade infantil e a neonatal ficam evidenciadas. São questões ligadas aos aspectos físicos, pois algumas adolescentes, com capacidade de reproduzir, ainda não estão prontas organicamente para a reprodução. Wong e Melo (1987) relacionam a mortalidade infantil e materna, embora seja geralmente aceita a ideia de que possam ser minimizadas com o acompanhamento pré-natal. Neste caso, não se trata de um grande problema, pelo menos nesse sentido, visto que hoje o campo médico é bastante evoluído nessa área, o que permite ser resolvido com o acompanhamento médico do pré-natal em encontros durante a gestação como aponta o Ministério da Saúde.

Porém, não se pode deixar de chamar a atenção de que sem um pré-natal surgem problemas que poderiam ser solucionados pelo acompanhamento médico sistemático, visto que "o acompanhamento resulta numa gravidez como outra qualquer e que a incidência de bebês prematuros e com baixo peso é quase idêntica à da população adulta" (ROCHA, 1998, p. 41).

Por outro lado, as implicações emocionais são marcantes, visto que os/as adolescentes ainda não elaboraram suficientemente seus afetos - devido às características do seu desenvolvimento psicológico anterior aos 12 anos passarem por uma ação bastante egocêntrica como nos mostra Freud em seus estudos: 'Três Ensaios Sobre a Teoria da Sexualidade Humana' (Obras Completas - tomo II). Ficam os/as mesmos (as), em sua maioria, perplexos (as), assustados (as) e angustiados (as) diante dessas situações prematuras e,

Walfrido Nunes Menezes, Marília Araújo, Maíra Souza e Rafaela Ingrid Melo 
quase sempre indesejada para o presente momento de vida em que os/as jovens se encontram.

Desta maneira, termina por ocorrer um processo de exclusão simbólica (psicossocial), uma vez que a garota é privada da adolescência em termos de estudos, diversão, lazer e namoro. A mesma fica presa ao filho, como apontou a pesquisa de Menezes (2002):

'Não pode ir para a rua"... "Não pode ir para festas, dançar, brincar"... "Não tem hora para comer, grávida tem hora para tudo"... "Deixei de fazer muita coisa: passear, andar, ir para praia"... "O corpo muda, geralmente engorda muito"... "Você perde o trabalho que tinha (grupo focal).

Os (as) adolescentes ainda estruturam sua identidade enquanto sujeito, portanto essa ruptura entre o mundo adolescente e a entrada precoce no mundo adulto termina por provocar uma desestruturação psicossocial que irá influenciar suas atitudes, visto que os/as mesmos (as) ainda apresentam relações instáveis.

Além dessas questões, não se pode deixar de apontar que um dos maiores problemas da gravidez na adolescência ainda giram em torno da baixa ou inexistente escolarização. Se não vejamos, evidenciase que $54 \%$ de adolescentes sem escolaridade já ficaram grávidas, o que reforça a ligação entre o nível de escolaridade e a gravidez, visto que implica um setor de conhecimento que é a fonte de desenvolvimento do ser humano. Por outro lado, apenas $6,4 \%$ das adolescentes com nove anos ou mais de escolaridade já têm o primeiro filho, ficam ou estão grávidas do mesmo.

No caso do Brasil, país de analfabetos e de história de fracassos e altas evasões, os aspectos ligados à gravidez na adolescência só tendem a se acentuar. Também segundo pesquisa desenvolvida em Caruaru, doze das adolescentes não concluíram o Ensino Fundamental de $1^{\mathrm{a}}$ a $4^{\mathrm{a}}$ série e sete de $5^{\mathrm{a}}$ a $8^{\mathrm{a}}$ série. Apenas uma chegou a $2^{\mathrm{a}}$ série do Ensino Médio (MENEZES, 2002).

Portanto, mesmo com a introdução em algumas escolas, não em sua maioria , da educação sexual, infelizmente, em geral essa fica ligada aos aspectos biológicos: doenças, fisiologia do corpo, métodos contraceptivos, etc. E, diante de tal quadro, precarização do conhecimento, é muito fácil a jovem não pensar em contraceptivos, escola e/ou trabalho, entregando-se ao discurso machista da função materna, que uma vez internalizado passa a fazer parte de seu cotidiano.

A maternidade como processo natural do feminino ocorre diante da capacidade de procriar da mulher; "a reprodução biológica dá um fundamento aparentemente natural à visão androcêntrica da divisão de trabalho sexual e da divisão sexual do trabalho (...)" (BOURDIEU, 1999, p. 33), respaldado pela crença de que:

é a particularidade do aparelho reprodutivo da mulher, que funciona em seu esquema explicativo como suporte para posturas de consagração da função materna, identificada como representante legítima e incontestável da feminilidade e fonte de realização inigualável (SANTOS, et al, 1996, p. 1 - 2).

Para Badinter (apud FORNA, 1999, p.40), "o amor materno nasce da relação mãe-fillho e é uma expressão do livre-arbítrio. O imenso amor que a maioria das mulheres sente pelos filhos é alimentado e apoiado pelos valores sociais e ambientais que existem hoje". Baixa escolarização, desconhecimento de como funciona o corpo humano, o papel materno e as especificidades psicossociais terminam por refletir em uma sexualidade ativa, mas escondida que só aparece quando a menina fica grávida, através da barriga, como no caso da:

adolescente M. de 16 anos, aluna de um colégio de freiras na zona Sul do Rio de Janeiro. O assunto, visto como tabu, foi considerado uma grande tragédia. A família foi chamada para receber a sugestão de tirar a menina da escola, M. optou por ficar, mas descobriu que o preconceito e o machismo já estavam enraizados na educação rigorosa e religiosa da escola. Suas amigas discretamente afastaram-se e os meninos tiveram a confirmação de que ela transava e passaram a assediá-la (ROCHA, p. 42 - 43).

O quadro, no Brasil e no mundo, espelha como é grande ainda o preconceito e a distância em torno da sexualidade no ocidente, terminando por se refletirem essas distorções que, em vez de somar, afastam e provocam mal-estar para os/as adolescentes. E para o filho deles (as) que, indiretamente, receberá toda uma carga emocional negativa da mãe e do pai que encontram dificuldades em elaborar a maternidade e paternidade na adolescência.

Esse fato aparece também junto às adolescentes que participaram da pesquisa em Caruaru (MENEZES, 2002). Em sua maioria, o ato sexual acontecia esporadicamente e sem um planejamento adequado, estando o casal desprovido da camisinha e de qualquer

Walfrido Nunes Menezes, Marília Araújo, Maíra Souza e Rafaela Ingrid Melo 
outro método contraceptivo.

Muitos garotos negam a paternidade. Outros não assumem e desaparecem. Aqueles que aceitam encontram muitas dificuldades, mesmo se casando. Portanto, a responsabilidade acaba sendo da mãe. A autoestima termina por ser prejudicada, repercutindo pelo resto de seus dias mesmo que case com o pai do bebê. Ficar sozinha com a situação implica uma sobrecarga maior, desequilibrando-a emocionalmente, repercutindo em seu próprio filho. Raras jovens apontam noutra direção, ou seja, apresentam desenvolvimento e maturidade que lhes permitem vivenciar a gravidez.

Essa colocação reflete muito bem o que já foi dito pelas adolescentes que participaram e participam do projeto de extensão. O prejuízo da vida da adolescente, em termos de desenvolvimento, face às várias transformações por que ela passa com a gravidez e o nascimento do bebê, o que termina por limitar a sua participação em festas, passeios, estudos, etc., portanto, uma exclusão simbólica.

$\mathrm{O}$ processo de exclusão tem amplitudes significativas na esfera pessoal e coletiva, tendo em vista que não se trata apenas de condições financeiras essa existe sim - mas de não ter acesso 'ao viver plenamente' com dignidade, ter relações carinhosas e amorosas, isto é, a felicidade em ser sujeito participante e ser reconhecido como tal, portanto simbólica.

Isso nos leva a constatar a falta de políticas públicas do governo federal, voltadas para a saúde e para o social. Na ausência de projetos de vida, a adolescente se apega a alternativa da maternidade, o que é possível para ela.

As condições de vida precária somadas ao machismo deixam as mulheres a mercê dos instrumentos sociais que lhes causam submissão, dependência e pouco espaço para questionamento, resultando, dessa forma, na exclusão simbólica e econômica.

Nesse sentido, a Conferência Internacional sobre População e Desenvolvimento (CIPD, apud MENEZES,2002, p. 176), em 1994, advertiu-nos que:

Sem a plena participação das mulheres em pé de igualdade, não pode haver desenvolvimento humano sustentável (...). O programa de ação sublinha a necessidade de igualdade e equidade entre os sexos e do apoio dos homens à atribuição de poderes às mulheres. Enuncia o direito à saúde reprodutiva universal e global, incluindo o planejamento familiar, e refere que, para as mulheres, a base essencial da atribuição de poderes é um contexto que também engloba a educação e o acesso aos cursos.

Assim sendo, teríamos um país mais consciente, solidário, humano e existirá o sujeito, enquanto cidadão. Não vemos outro caminho a não ser novas atitudes no eixo família / sociedade/ escola, para possibilitar aos adolescentes uma maior compreensão do mundo, buscando assim, satisfação de necessidades num sentido amplo, material e imaterial, como propõe Sposati (1999).

Essa exclusão tem como referência básica a pobreza e a pouca escolaridade. Onde está a perspectiva de futuro? A pobreza promove a falta de estruturas básicas como saúde, educação, condições de vida digna, lazer, etc. Faltam às adolescentes projetos que visem à qualidade de vida (sonhos).

$\mathrm{Na}$ falta de um projeto de vida viável e real, aparece a "construção de projetos empobrecidos, além de frágeis e submissos, que cerceiam as possibilidades de incursões efetivas na esfera pública, cumprindo as expectativas sociais do ser feminino" (SCARPARO, 1994, p. 72). Nas classes populares, tais situações implicam a manutenção da reprodução da pobreza. Os índices de gravidez são mais elevados entre jovens analfabetos que teriam possibilidade quase nula de escapar do círculo da miséria (MADEIRA e WONG, apud LYRA, 1998).

Nesse sentido, ocorre a fragmentação do processo de

autoimagem e a autoestima, pois as percepções e os sentimentos de si mesmo estabelecem parâmetros importantes para a avaliação de experiências passadas, bem como para iniciativas de articular um novo projeto, a partir dessa avaliação (...) o projeto de vida é a possibilidade que se cria. Sua consecução e reavaliação implicam contato com a realidade, além de coragem e energia suficientes para transformá-la. Em decorrência, projeto de vida e sua reavaliação resultam da interação entre construções pessoais e condições sociais (SCARPARO, 1994, p. 73).

Não se pode esquecer:

o sujeito humano é criador de projetos, o que o leva a participar de sua cultura, de sua história e a ser sujeito de seu corpo. Participar de projetos, imaginá-los, sonhálos, realizá-los, elaborá-los, destruí-los, abandoná-los representa laborar na

Walfrido Nunes Menezes, Marília Araújo, Maíra Souza e Rafaela Ingrid Melo 
construção da civilização (CARRETEIRO, 1999, p.91).

\section{Preconceitos, tabus e dogmas}

Em torno destes tópicos apontados acima, percebemos ainda, influenciando tanto na gravidez adolescente, bem como, no conjunto da sexualidade humano em torno da mulher, a questão de Gênero, que tem pontuado preconceitos, dogmas e exclusões do universo feminino da participação do processo de construção socioeconômico e político do país.

Portanto, diante de tais aspectos precisamos pensar no desenvolvimento de políticas públicas de gênero na educação, para abrir espaços na construção integrada de novas relações sociais no conjunto da sociedade. Assim, cabe examinar se as políticas educacionais desenvolvidas no país têm contribuído para a redução do processo de alienação e exclusão social, em especial das mulheres das classes populares, inseridas num contexto de pobreza e discriminação e, portanto, excluídas como classe e como gênero.

Antes de qualquer coisa, entretanto, é importante conhecer o processo de construção da identidade social de gênero, que tem como base princípios históricos, ideológicos, políticos, sociais e culturais, nos quais ela foi se estruturando. $\mathrm{O}$ conceito de papéis de gênero refere-se ao conjunto de expectativas sociais sobre os comportamentos 'adequados' e 'claramente' distintos que a pessoa deverá manifestar, conforme o sexo a que pertence. Os gêneros ao longo da história da humanidade, sempre foram pautados por relações que implicam uma constante desigualdade e segmentação entre o feminino e o masculino. Embora essas relações tenham passado por mudanças significativas a partir da segunda metade do século XX, com o avanço dos movimentos feministas, estas ainda não contemplam a totalidade do universo feminino.

Passo a passo, efetivas mudanças começaram a acontecer para as mulheres a partir das décadas de 1950 e 1960, quando o mundo passou por grandes transformações, tais como os movimentos hippie e feminista, a descoberta da pílula e, com isso, a separação entre sexualidade e reprodução. Em decorrência, pequenas conquistas foram afetando e mudando a realidade feminina, como a entrada cada vez maior de mulheres na universidade e no mercado de trabalho. Cabe ressaltar aqui, a importância e significado que teve, para os movimentos feministas, a publicação, em 1949, do livro 'O Segundo Sexo', de Simone de Beauvoir, tratando da questão feminina.

Tomando Saffioti (1992, p. 211) como referência, pode-se dizer que gênero é "um processo infinito de modelagem-conquista dos seres humanos, que tem lugar na trama de relações sociais entre mulheres, entre homens e entre mulheres e homens." Segundo a autora:

O conceito de relação de gênero deve ser capaz de captar a trama de relações sociais, bem como as transformações historicamente por ela sofridas através dos mais distintos processos sociais, trama esta na qual as relações de gênero têm lugar (SAFFIOTI, 1992, p. 187).

É no bojo dessas relações sociais que se vai construindo a identidade de gênero. Ela começa no nascimento e vai se estruturando na infância, adolescência e idade adulta, no trato das relações sociais, familiares e na educação escolar. De acordo com Bourdieu (1999, p. 34): "cada um dos dois gêneros é produto do trabalho de construção diacrítica, ao mesmo tempo teórica e prática, que é necessário à sua produção como corpo socialmente diferenciado do gênero oposto, sob todos os pontos de vista culturalmente pertinentes". Tais estruturas organizaram-se também em torno do sistema econômico, apoiando-se na ideia de propriedade privada, bem como na continuidade da herança, portanto, no patriarcado. Os homens, historicamente, se apropriaram do poder, que lhes concedia o pleno e total direito sobre a mulher e a prole.

Assim, a percepção de gênero é inserida em um modelo de submissão da mulher diante do homem, reflexo de um longo, permanente e exaustivo processo de opressões e condicionamentos sociais. O "Sexismo não é somente uma ideologia, reflete, também, uma estrutura de poder, cuja distribuição é muito desigual, em detrimento das mulheres" (SAFFIOTI, 2004, p. 35). Além do mais: "as relações patriarcais, suas hierarquias, sua estrutura de poder contaminam toda a sociedade, o direito patriarcal perpassa não apenas a sociedade civil, mas impregna o Estado" (SAFFIOTI, 2004, p. 54).

De acordo com a autora:

Não há, de um lado, a dominação patriarcal e, de outro, a exploração capitalista. Para começar, não existe um processo de dominação separado de outro de exploração. Por esta razão, usa-se, aqui e em outros textos, a expressão dominação-exploração ou exploração-dominação (2004, p. 130).

Na visão de Bourdieu (1989), como o poder é também simbólico, reflete-se em todos os âmbitos da sociedade, gerando desigualdades na maioria das vezes

Walfrido Nunes Menezes, Marília Araújo, Maíra Souza e Rafaela Ingrid Melo 
difíceis de serem modificadas. De acordo com esse autor (1998), o poder é um processo invisível, que ocorre onde menos se espera e no mais profundo do ser, isto é, "[...] pode ser exercido com a cumplicidade daqueles que não querem saber que lhe estão sujeitos ou mesmo o exercem." (BOURDIEU, 1998, p. 8). Desta forma, o machismo não se organiza unicamente em torno do homem, mas faz parte também do discurso de muitas mulheres. Ele raramente é questionado por grande parte delas.

Como apontou Saffioti:

Imbuídas da ideologia que dá cobertura ao patriarcado, mulheres desempenham, com maior ou menor frequência e com mais ou menos rudeza, as funções do patriarca, disciplinando filhos e outras crianças ou adolescentes, segundo a lei do pai. Ainda que não sejam cúmplices deste regime, colaboram para alimentá-lo (2004, p. 102).

Balizado pelo patriarcado, fortalecido pela religião e pelo Estado, o processo androcêntrico e capitalista perpetuou e continua perpetuando atitudes e posturas sexistas, que restringem tanto as mulheres como os homens. Assim, as meninas e os meninos, desde a mais tenra idade, vão incorporando os procedimentos e realizando as interpretações dos papéis sociais de gênero que cada um deve desempenhar em seu meio já preestabelecidos nos seus contextos de vida e apreendidos e internalizados na educação familiar, bem como ampliados e reforçados no processo de socialização e de educação escolar.

Para Bourdieu (1999), tal processo surge em função de uma visão "interacionista" ou mecanismo de vocação/cooptação psicossociológica, que ignora as condições sociais de produção e ajusta os agentes ao seu posto ou às suas atitudes:

Quando os dominados aplicam àquilo que os domina esquemas que são produtos da dominação ou, em outros termos, quando seus pensamentos e suas percepções estão estruturados de conformidade com as estruturas mesmas da relação da dominação que lhes é imposta, seus atos de conhecimento são, inevitavelmente, atos de reconhecimento, de submissão (BOURDIEU, 1999, p. 22).

Portanto, a identidade de gênero da mulher e do homem incorpora os comportamentos que foram e são traçados ao longo da história da humanidade e reforçados pela educação escolar, definindo e estruturando os papéis sociais em que cada um dos sexos deverá agir interagir e expressar sua feminilidade e masculinidade no mundo.

\section{Metodologia}

O presente trabalho de extensão foi e é realizado numa proposta metodológica participativa, construtiva e social. Dessa maneira, pode-se ter uma maior compreensão sobre a gravidez na adolescência e como a mesma implica um processo de exclusão social, a partir do olhar do/da juventude, que expressa um sentimento e rompe, assim, com o discurso médico científico, psicológico e técnico, com uma visão única a partir da compreensão do ser adulto.

O trabalho foi e será realizado através de técnicas da dinâmica de grupo, observação não participante e a utilização de do grupo focal. O presente trabalho de intervenção se inicia por meio de duas técnicas de grupo - que trabalham com o lúdico, o que possibilita uma maior participação e integração, além de quebrar algumas resistências possíveis diante do tema em si. A primeira, estabelece o contato inicial com os/as adolescentes para promover o conhecimento, ao mesmo tempo que, ao final do trabalho, será esclarecido o objetivo de estar ali e o que se pretende atingir; na segunda (em dois momentos), será trabalhada no grupo uma outra técnica para que os/as mesmos (as) possam expressar suas visões sobre a "adolescência" e a "gravidez na adolescência". Esses encontros permitirão a compreensão de alguns elementos referentes ao tema, o que orientará o desenvolvimento do presente trabalho, complementado pelo sociodrama.

A observação não-participante ocorre desde o primeiro momento, quando do encontro como o grupo dos adolescentes integrados ao Projeto Espaço Recriar e Agente de Cidadania em dezembro de 2005 até a presente dada e, ocorre durante todo o processo de desenvolvimento do trabalho, a fim de se incorporar, sempre que necessário, a percepção e o entendimento do grupo de adolescentes envolvidos, isto é, de ver o mundo através dos olhos dos próprios jovens.

Bruyn (apud HAGUETTE, 1981, p. 58) diz:

a observação representa um processo de interação entre teoria e métodos dirigidos pelo pesquisador na sua busca de conhecimento não só da 'perspectiva humana' como da própria sociedade (...) enfatiza a necessidade de se reconhecer em primeira instância o caráter peculiar dos seres humanos, seu comportamento e sua vida em grupo.

Walfrido Nunes Menezes, Marília Araújo, Maíra Souza e Rafaela Ingrid Melo 
E, por último, temos o grupo focal. Esta técnica foi e é desenvolvida pelo fato de proporcionar sessões de grupo:

como um dos focos facilitadores da psicossociológicas e culturais, prevendo a obtenção de dados a partir de discussões cuidadosamente planejadas, nas quais os participantes podem expressar suas percepções, crenças, valores, atitudes, representações sociais sobre uma questão específica, num ambiente propício e não ameaçador, permitindo ao pesquisador, neste contato, o conhecimento do ponto de vista dos mesmos (WESTPHAL, et al. , 1996, p.473).

A importância do grupo focal está em promover um:

conhecimento prévio dos problemas segundo o ponto de vista da população (...) e pela flexibilidade. Em vez de seguir um roteiro rígido de questões (...) o moderador tem a liberdade para modificar a ordem das questões (...) e possibilita ainda a emergência de conflitos (...) (id., p. 478 - 79).

O processo em si tem a preocupação de tentar captar as informações não-verbais, possibilitando ao mesmo tempo pensar coletivamente um tema de relevância social, na opinião do próprio grupo envolvido.

Através desses procedimentos será observada a possibilidade de inter-relação do grupo, na medida em que a juventude se posicionar sobre o tema adolescência, gravidez e exclusão. Na medida em que cada um se coloca, outro aprofunda e traz à tona outras reflexões, complementando as informações dadas. Permite a livre expressão dos sujeitos através da apropriação de seu discurso.

\section{Considerações Finais}

Buscamos, a partir do pensamento, fala e compreensão da gravidez adolescente pelas adolescentes das classes populares, constatar que as reações são bastante diferenciadas. Uma adolescente engravida, duas atitudes se expressam. A garota diz: 'vou ser mãe', o rapaz diz: 'minha namorada está grávida, e agora?' A menina já incorpora o estado no primeiro momento; o rapaz, por sua vez, questiona na maioria das vezes se o filho é seu.
Nesse jogo de apostas, mulheres e homens estão bem distantes, enquanto ela 'está' ele nem 'chegou'. Ocorre nesse contexto o primeiro movimento de exclusão por parte do companheiro que junto a ela não tinha planejado e nem pensado sobre este aspecto, como mostram o discurso da maioria das adolescentes.

Faz parte da Constituição a garantia de uma qualidade de vida, que favoreça os indivíduos na plena existência do viver, como por exemplo, o trabalho educativo que visa proporcionar aos adolescentes uma maior compreensão da vida e do mundo, instigando-os para o livre pensar, para a compreensão crítica da realidade, para a sua participação do processo de construção de sua história social e de vida.

Para tal, tornou-se importante pensar e repensar a adolescência, em seu contexto sociocultural, possibilitando uma nova leitura e releitura dos preconceitos, tabus e dogmas, e não prevalecendo as concepções técnicas do mundo 'adulto', e sim o contexto de vida em que estão inseridas as adolescentes. Existe uma lacuna muito séria entre o diálogo e a ação, pois quando se está num plano teórico, tudo é normal e saudável; quando a ideia vira prática, sugere a ameaça a própria integridade da família e do meio social.

A falta de diálogo e comunicação - não esquecendo os conflitos socioeconômicos como pobreza, miséria e exclusão social - na relação pais e filhos termina por estabelecer uma distância na organização da identidade dos filhos e o fosso criado resulta na desorganização do ser humano, que fica sem parâmetros básicos e essenciais para a sua formação, sócio educacional e pessoal.

A família, cada vez mais, perde suas referências do grupo social local - o espaço da cidade, da rua, dos amigos. Perdendo no espaço, apega-se a valores contraditórios de um modelo social fragmentado e distorcido, que implica rupturas com os elos comunitários anteriormente estabelecidos.

O importante é a qualidade de vida que se organiza dentro de uma perspectiva construtiva e humana, para que o sujeito possa elaborar e reelaborar o mundo e a vida, participando da construção político - social como agente atuante - o ser cidadão - e não excluído de uma possibilidade digna de viver.

Cabe ao adolescente a possibilidade de responder aos seus questionamentos e junto com adultos buscarem caminhos e soluções dos problemas, no sentido de perceber e reconhecer sentimentos que possam encarar as atitudes com o apoio da família, da sociedade e da escola.

A participação da construção social proporciona ao indivíduo ser sujeito da sua vida. Para tanto, implica a necessidade do diálogo, da conversação com os filhos a

Walfrido Nunes Menezes, Marília Araújo, Maíra Souza e Rafaela Ingrid Melo 
fim de que possam integrar os conhecimentos familiares aos do seu meio (grupos, atividades sociais, escola, etc.), desenvolvendo sua identidade.

As ações da esfera social contribuíram para o enriquecimento da prática de organização coletiva, ampliando assim, o espaço do grupo de jovens para a obtenção de uma atitude participativa, para o desenvolvimento de senso crítico e a sistematização do saber.

A tomada de consciência é o primeiro passo para a modificação de qualquer comportamento, ideia, atitude, para o sujeito construir o seu conhecimento. A perspectiva de crescimento torna-se viável a partir do momento em que as adolescentes pensem sobre o assunto, levantando suas hipóteses com seus acertos e erros, mas sem uma preocupação com a exatidão das questões.

O exercício pleno da cidadania facilita ao ser humano uma nova leitura e análise crítica da sociedade, dada a sua relevância para a organização social da comunidade que, sem esse princípio básico termina por estruturar aspectos de marginalidade e exclusão.

Reverter à situação atual é um passo lento e longo. A história não se fez e nem se faz de um dia para o outro, mas é na luta cotidiana e permanente que poderemos construir uma história participativa, consciente, dinâmica e afetiva.

Por outro lado, a maior dificuldade é a permanência dos participantes ao longo do projeto no grupo do Projeto Recriar. Este afastamento pode ocorrer em virtude de uma possível resistência em refletir e debater assuntos que permeiam o campo da sexualidade, afinal as ideias propostas podem ser bastante diferentes das que já são concebidas por eles como certas ou erradas. Para isto, procuramos conhecer a realidade daqueles que participam do projeto, abordando o tema da maneira mais próxima possível do cotidiano dos mesmos, com tempo e bastante cautela para efetivarmos de forma satisfatória as atividades, dando andamento ao projeto.

Porém, podemos concluir que tem sido bastante satisfatório o resultado do projeto. Ao longo do tempo, a participação vai crescendo, os participantes interagem de maneira mais efetiva e, muitas vezes, relatam o quanto à experiência de participar está sendo importante. Muitas dúvidas são tiradas, fazendo com que os/as participantes procurem modificar atitudes errôneas que praticavam, visto que um dos objetivos do projeto é educar e promover a participação crítica e criativa, para uma vivência mais sadia da sua própria sexualidade.

$\mathrm{O}$ presente trabalho explicita as atividades desempenhadas, objetivos preestabelecidos, assim como as principais dificuldades enfrentadas ao longo da execução do mesmo. Sua realização está longe se ser uma simples atividade, uma vez que abordar a temática da sexualidade pode mobilizar certas resistências, por ser um assunto pouco difundido no cotidiano dos indivíduos, tendo em vista a escassez de informações e formações que estas pessoas possuem.

\section{Referências}

BARROSO, Carmem; BRUSCHINI, Cristina. Sexo e Juventude. Como discutir a sexualidade em sua casa e na escola. São Paulo: Cortez, 1998.

\section{BAUDRILlARD, Jean. A Sociedade de Consumo.} Rio de Janeiro: Elfos, 1995.

BERQUÓ, Elsa. Arranjos familiares no Brasil: uma visão demográfica. In: SCHWARCK, Lilia Moritz. Historia da vida privada no Brasil: contrastes da intimidade contemporânea. São Paulo: Companhia das Letras, 1998, p. 411-438.

BRASIL. Ministério da Saúde. A Adolescente Grávida e os Serviços de Saúde no Município. Brasília, s.d. Disponível em: $<$ http://www.saude.gov.br/>. Acesso em: 08 jun. 1998.

BOURDIEU, Pierre. A dominação masculina. Rio de Janeiro: Bertrand Brasil, 1999.

BOURDIEU, Pierre. O Poder Simbólico. 3. ed. Lisboa: Difel, 1989.

BOURDIEU, Pierre. Sobre a Televisão. Rio de Janeiro, Jorge Zahar, 1997.

CARRETEIRO, Tereza Cristina. A Doença como Projeto. Uma contribuição à análise de formas de afiliação e desfiliação sociais. In SAWAIA, Bader (Org.). As Artimanhas da Exclusão - Análise psicossocial e ética da desigualdade social. Petrópolis: Vozes, 1999, p. 27 - 50.

CHAUI, Marilena. Repressão Sexual - Essa nossa (des)conhecida. 3. ed. São Paulo: Brasiliense, 1984.

CHAVES, Jaqueline. 'Ficar Com' - Um estudo sobre o novo código de relacionamento no Brasil. Rio de Janeiro: Revan, 1997.

DURAND, Dominique . Gravidez na Adolescência. Novidade ou Reprodução Social? Recife: UFPE, 1997.

Walfrido Nunes Menezes, Marília Araújo, Maíra Souza e Rafaela Ingrid Melo 
FORNA, Aminatta. Mãe de Todos os Tipos. Como a sociedade modela e reprime as mães. Rio de Janeiro: Eudioro, 1999.

FREUD, Sigmund. Obras Completas. Biblioteca Nueva: Madri, 1973.

HAGUETE, Teresa Maria Frota . Metodologias Qualitativas na Sociologia. Petrópolis: Vozes, 1987.

LYRA, Jorge Luiz Cardoso. Paternidade Adolescente. Uma proposta de intervenção. São Paulo: 1997. 182 p. Dissertação de Mestrado em Sociologia. (Departamento de Sociologia), Pontifícia Universidade Católica de São Paulo.

MENEZES, Walfrido Nunes . A Barriga Cresceu...Adeus Meninas! - Exclusão social: do real ao simbólico na gravidez adolescente. João Pessoa/PB: Ideia, 2002.

NERDE, Gizlene. Ajustando o Foco das Lentes: um novo olhar sobre a organização das Famílias no Brasil. In. Kalovstian, Silvio. (Org.). Família Brasileira, a Base de Tudo. São Paulo: Cortez / Brasília, UNICEF, 1998, p. $26-46$.

NOLASCO, Socrates. O Mito da Masculinidade. Rio de Janeiro: Rocco, 1993.

ORGANIZAÇÃO MUNDIAL DA SAÚDE. Gravidez na Adolescência no Mundo. São Paulo, Projeto Aprendiz, 1999. Disponível em: $<$ htt://www.uol.com.br/aprendiz/>. Acesso em: $21 \mathrm{dez}$. 1999.

REMÉDIOS, T. Ética e Criança na TV. São Paulo: Projeto Aprendiz, 1997. Disponível em $<$ http://www.uol.com.br/aprendiz/> Acesso 14 de julho 1998.

ROCHA, Amarilis. Erotização do dia a dia eleva o número de adolescentes grávidas. Cadernos Brasil Comportamento, $\mathrm{n}^{\mathrm{o}}$ 205, Rio de Janeiro, 1998.

SAFFIOTI, Heleieth. Rearticulando Gênero e Classes Sociais. In: $\mathbf{1 4}^{\mathbf{0}}$ ENCONTRO da ANPOCS. Caxambu: ANPOCS, 1992.

SAFFIOTI, Heleieth. Gênero, patriarcado, violência. São Paulo: Fundação Perseu Abramo, 2004.

SANTOS, F. Identidade. In: TAP, Pierre. Relações Interpessoais e Gênese da Identidade. Homo XVIII
- XIX, Fac. 2, Toulose, 1979, p. 6 - 43.

SANTOS, F. A Construção da Representação Social. Recife, 1996.

SCARPARO, Helena Beatriz Kochenborger. O Projeto de Vida de Mulheres de Classes populares e Sua Relação com a educação. Porto Alegre, 1994. 186 p. Dissertação de Mestrado em Educação (Faculdade de Educação) Pontifícia Universidade Católica do Rio Grande do Sul.

SPOSATI, Aldaíza . Cidadania e comunidade solidária. Serviço Social e Sociedade, São Paulo, v. 16, n. 48, p. 124-147, ago. 1999.

WESTPHAL, Marcia Faria. (et al). Grupos Focais: experiências precursoras do uso da técnica em programas educativos em saúde no Brasil. São Paulo, 1995.

WONG, Laura; MELO, Aparecida Vieira de. Gravidez na Adolescência. São Paulo: Fundação Sistema Estadual de Análise de Dados - SEADE, 1987.
Recebido em 8 de junho de 2011. Aceito em 24 de junho de 2012.

Walfrido Nunes Menezes, Marília Araújo, Maíra Souza e Rafaela Ingrid Melo 